\title{
Hydrogen bonded supramolecular polymers in moderately polar solvents
}

\author{
Farid Ouhib, ${ }^{a, b}$ Matthieu Raynal, ${ }^{a, b}$ Benjamin Jouvelet, ${ }^{a, b}$ Benjamin Isare, ${ }^{a, b}$ and Laurent Bouteiller*a,b
}

Hydrogen bonded assemblies are usually decomposed by polar organic solvents. However, we have succeeded in preparing a strongly associated supramolecular polymer which forms viscous solutions in competitive solvents such as 10 tetrahydrofuran.

Hydrogen bonded assemblies are significantly weakened in polar solvents. ${ }^{1-3}$ This has been shown to be due mainly to the competition between solute-solute and solute-solvent hydrogen bonds. ${ }^{4,5}$ For instance, the association constant 15 between perfluoro-tert-butyl alcohol and tributylphosphine oxide has been shown to decrease from $>10^{5} \mathrm{M}^{-1}$ in cyclohexane to $240 \mathrm{M}^{-1}$ in tetrahydrofuran. ${ }^{4}$ Although this effect is unquestionably real, it has been widely overinterpreted as meaning that solute-solute hydrogen bonds are 20 too weak in polar solvents to maintain stable assemblies. As a consequence, purely hydrogen bonded systems are rarely envisaged for the design of supramolecular systems in polar solvents. In water or very polar solvents like DMSO, hydrogen bonds have been used in association with 25 solvophobic interactions, ${ }^{6,7} \pi$-stacking ${ }^{8-11}$ or ionic interactions. $^{12-15}$ In less polar solvents like acetone, hydrogen bonds have been used in association with dipolar interactions. ${ }^{16,17}$ Supramolecular assemblies in polar solvents maintained exclusively by hydrogen bonding are rare 30 indeed, ${ }^{18-21}$ but these few examples remind us that this is nevertheless a possibility.

Supramolecular polymers, i.e. chains of small molecules held together through reversible non-covalent interactions, ${ }^{22}$ can form viscous solutions or viscoelastic gels useful for 35 many applications. The range of known supramolecular polymers with interesting rheological properties in polar organic solvents like ethers, esters or ketones is very limited, ${ }^{16,23}$ and none are based on hydrogen bonds alone, probably because the expected weakness of hydrogen bonds in 40 polar solvents has discouraged research in this area. However, hydrogen bonds offer the distinct advantages of directionality and versatility, and applications of rheology additives in polar media are important in fields such as coatings. ${ }^{24}$ Therefore, we have tried and designed a supramolecular polymer assembled 45 from sufficiently strong hydrogen bonds, in order to form long chains even in polar solvents.

Bis-urea 1 (Scheme 1) was shown to form supramolecular polymers in low polarity solvents such as dodecane, ${ }^{25}$ toluene, ${ }^{26}$ and chloroform. ${ }^{27}$ However, in more polar solvents,

${ }_{50} \mathbf{1}$ is either insoluble (in ethyl acetate) or not self-assembled because of hydrogen bonding to the solvent (in tetrahydrofuran). Previous molecular simulation studies suggested that it is possible to significantly strengthen the hydrogen bonds between urea groups in this bis-urea scaffold 55 by introducing methyl groups in ortho position to the urea. This modification forces the urea groups to leave the plane of the aromatic spacer and preorganizes the monomer in a more suitable conformation for assembly. ${ }^{28}$ Therefore, we synthesized bis-ureas $\mathbf{2}$ to $\mathbf{4}$ with methyl substituents at 60 various positions on the aromatic spacer to improve selfassociation and with oxygen containing side chains ${ }^{29}$ to improve solubility in polar solvents. Solubility tests show (Table S1) that bis-urea 3 is more soluble in polar solvents than the other bis-ureas: it dissolves spontaneously (without ${ }_{65}$ heating) in a large range of solvents where it forms a gel or a viscous solution. We therefore focused our study on bis-urea 3 and measured the viscosity of its solutions in several solvents (Fig. 1).

Scheme 1

As expected, the viscosity of the solutions decreases when

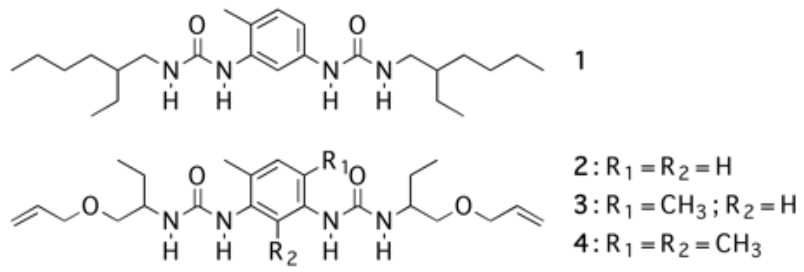

the polarity of the solvent increases. However, even in methylethyl ketone, a significant viscosity is measured at moderate concentrations $\left(\eta / \eta_{0}=3.8\right.$ for $[3]=10 \mathrm{mM}=4.5$ $75 \mathrm{~g} / \mathrm{L}$ ). This means that even in this competitive solvent, assemblies with a large hydrodynamic radius are formed. The large size of the assemblies was confirmed by dynamic light scattering (Fig. S2). In DMSO, the viscosity of the solutions is negligible, however, in chloroform/DMSO mixtures gels or 80 highly viscous solutions are obtained, depending on the proportion of DMSO (Fig. 1b and S1).

The structure of the assemblies was investigated by small angle neutron scattering (SANS). The scattering curve for 3 in deuterated ethyl acetate (Fig. 2) is characterized at low angles ${ }_{85}$ by a $\mathrm{q}^{-1}$ dependence covering more than a decade, typical of long fibrillar scatterers. The characteristic dimensions of the scatterers were deduced from a fit according to a model valid for long and rigid isolated fibrillar species with a circular cross-section and a uniform scattering length density 90 profile. ${ }^{30,31}$ The fit yielded the following values: diameter of the cross-section $28 \AA$ and linear density $\mathrm{n}_{\mathrm{L}}=0.36 \AA^{-1}$, which corresponds to $1.7 \pm 0.4$ bis-urea molecules in the crosssection. ${ }^{32}$ The objects are locally rigid rods (over a length of at least $10 \mathrm{~nm}$ ), but their overall shape and length cannot be 
determined from this data. Interestingly, exactly the same scattering curves are obtained for solutions of $\mathbf{3}$ in deuterated toluene and dichlorometane (Fig. S3). This means that the polarity of the solvent does not affect the local structure of the 5 assemblies, but only their length. In contrast, the low SANS intensity and flat profile for $\mathbf{2}$ at small angles (Fig. 2) is characteristic for small globular scatterers. A fit was performed with the form factor of a sphere, and yielded a diameter of $24 \AA$, which is in agreement with the largest 10 dimension of the fully extended molecule ( $22 \AA)$. Therefore, bis-urea 3 self-assembles into very long cylindrical objects, whereas bis-urea $\mathbf{2}$ does not self-assemble significantly in moderately polar solvents such as ethyl acetate.

a)

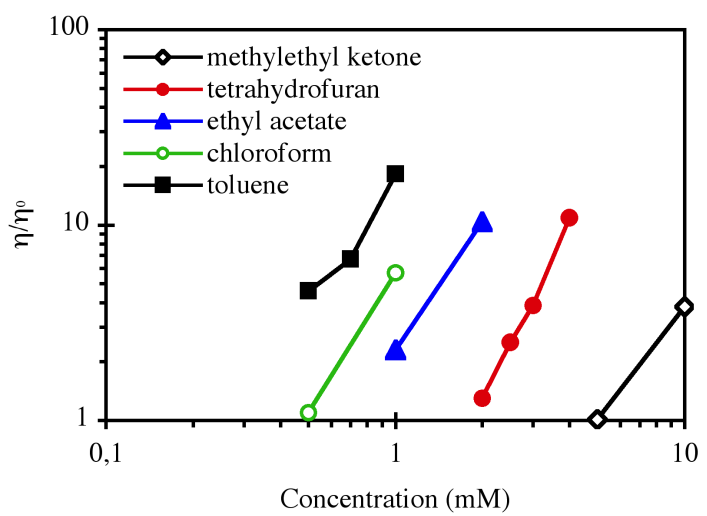

b)

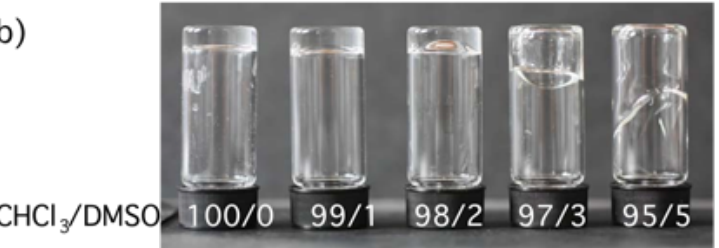

Fig. 1 (a) Relative viscosity versus concentration for solutions of $\mathbf{3}$ at $25^{\circ} \mathrm{C}$. (b) Photographs of solutions in chloroform/DMSO mixtures $([3]=$ $40 \mathrm{mM}=18 \mathrm{~g} / \mathrm{L}$ ), 1 minute after inverting the vials.

FTIR spectroscopy was used to check that hydrogen 20 bonding is indeed involved in the assemblies. Fig. 3 shows the spectra in the region of $\mathrm{N}-\mathrm{H}$ stretching vibrations, obtained for solutions of $\mathbf{2}$ or $\mathbf{3}$ in ethyl acetate. In the case of $\mathbf{3}$, two bands are detected with maxima at 3330 and $3272 \mathrm{~cm}^{-1}$ that can be assigned to hydrogen bonded $\mathrm{N}-\mathrm{H}$ functions. In 25 contrast, the main band for 2 has its maximum at $3410 \mathrm{~cm}^{-1}$. This value is intermediate between the values for free $\mathrm{N}-\mathrm{H}$ groups $\left(3444 \mathrm{~cm}^{-1}\right)$ and inter-urea hydrogen bonded $\mathrm{N}-\mathrm{H}$ groups $\left(3340 \mathrm{~cm}^{-1}\right)$ and can therefore be assigned to weakly hydrogen bonded $\mathrm{N}-\mathrm{H}$ groups, probably to the solvent. ${ }^{27,33}$

30 This result is in agreement with the viscosity and SANS data that show that $\mathbf{2}$ is not significantly self-assembled in ethyl acetate. Moreover, it demonstrates the presence of intermolecular hydrogen bonds in the case of $\mathbf{3}$ even in the presence a competing polar solvent. This is also confirmed by ${ }_{35}$ Fig. S4 that shows that the maximum of absorption for $\mathrm{N}-\mathrm{H}$ functions of $\mathbf{3}$ is not affected when the solvent is changed from toluene to ethyl acetate or tetrahydrofuran.

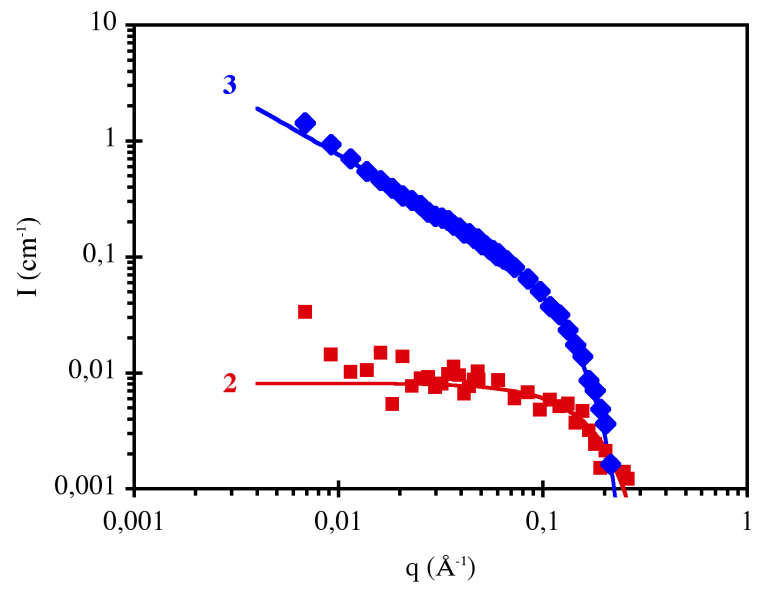

Fig. 2 SANS intensity versus scattering vector for $12 \mathrm{mM}$ solutions of 40 bis-ureas $\mathbf{2}$ or $\mathbf{3}$ in $\mathrm{d}_{8}$-ethyl acetate. The curves are fits according to a model for infinitely long rigid rods of diameter $28 \AA$ (blue), or for spheres of diameter $24 \AA$ (red).

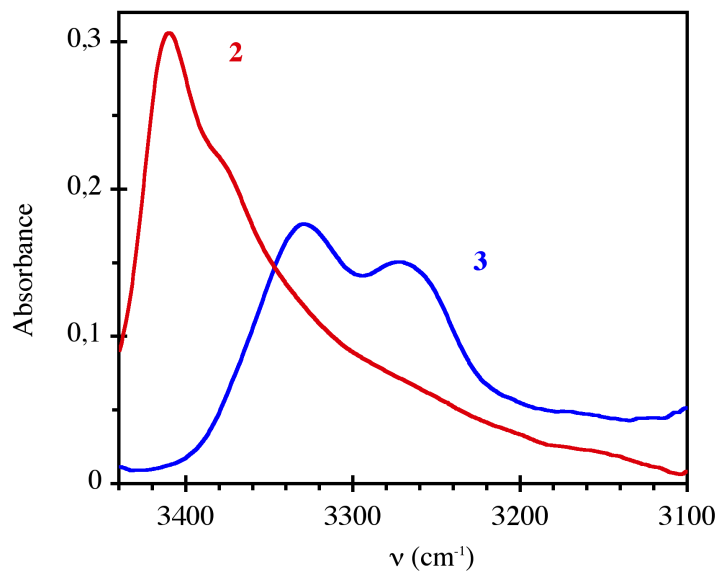

Fig. 3 FTIR spectra for solutions of $\mathbf{2}$ or $\mathbf{3}$ in ethyl acetate at $10 \mathrm{mM}$ at 45 $20^{\circ} \mathrm{C}$.

Formation of very long fibrillar objects by self-assembly of low molar compounds is well known in the field of organogelators. In this context, it is not rare to find compounds that self-assemble by hydrogen bonding and form 50 gels even in polar competing solvents. ${ }^{34}$ However, these systems are not dynamic: the fibrils are typically 10 to $100 \mathrm{~nm}$ thick so that breaking and reformation of the objects does not occur at temperatures well below the melting point of the gel. Moreover, for such thick objects, crystal packing forces are 55 very important and hydrogen bonding is never the only interaction present. In order to assess the dynamic character of our assemblies, we performed isothermal titration calorimetry (ITC) experiments, where a relatively concentrated solution of 3 in ethyl acetate was diluted into ethyl acetate. Fig. 4 shows ${ }_{60}$ the strongly endothermal effect associated with the dilution of the solution. The value of the enthalpy measured $\left(\Delta \mathrm{H}_{\text {dissoc }}=\right.$ $22 \mathrm{~kJ} / \mathrm{mol}$ ) is in agreement with the breaking of four hydrogen bonds per monomer. ${ }^{26,35}$ Moreover, after each injection, the signal smoothly reaches the baseline within a minute, which ${ }_{65}$ proves the dynamic character of the assembly. This 
experiment also yields the critical concentration below which the assembly is not stable: at $25^{\circ} \mathrm{C}$, bis-urea $\mathbf{3}$ self-assembly is possible only above $0.3 \mathrm{mM}$, and this critical concentration increases regularly with the temperature. This critical 5 concentration is compatible with the viscosity data.

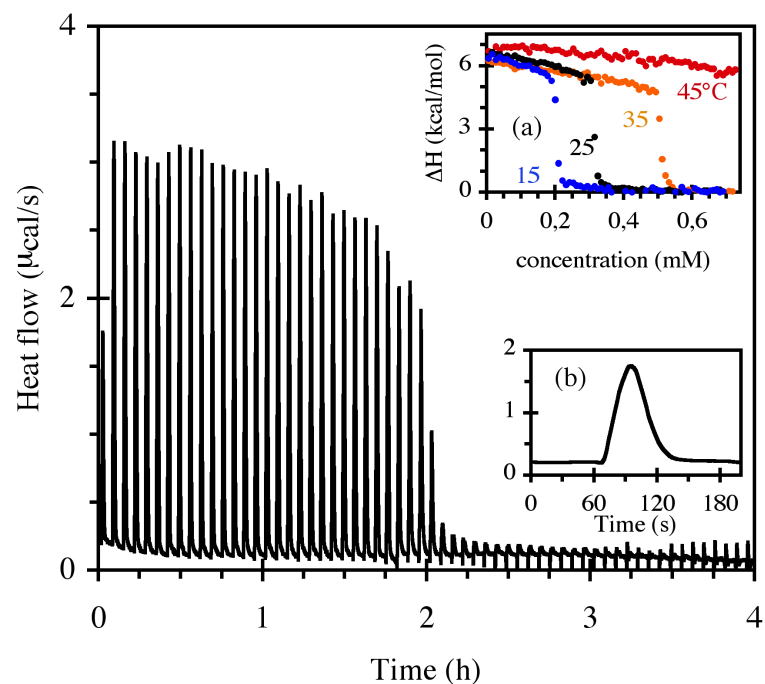

Fig. 4 Heat effect produced by injecting $4 \mu \mathrm{L}$ aliquots of a $4 \mathrm{mM}$ ethyl acetate solution of bis-urea $\mathbf{3}$ into ethyl acetate (ITC). The insets show the integrated signal versus concentration in the cell, for experiments 10 performed at various temperatures (a) and a zoom of the first injection

In conclusion, we have designed a new supramolecular polymer based on hydrogen bonding. The directionality of this interaction allows at the same time a strict control of the 15 structure of the assembly and a pathway for fast dynamics. As far as we know, this is the first example of a dynamic supramolecular polymer in moderately polar organic solvents that is efficiently stabilized only by hydrogen bonding. Our results demonstrate that the fine tuning of the hydrogen 20 bonding group can yield strongly associated systems, even in the presence of competitive solvents. The strong association between monomers is translated at the macroscopic level by the formation of highly viscous solutions in ethyl acetate, tetrahydrofuran or methylethyl ketone, at concentrations 25 below 1 weight percent.

We thank François Boué (LLB, Saclay) for assistance with SANS experiments.

\section{Notes and references}

${ }^{a}$ UPMC Univ Paris 06, UMR 7610, Chimie des Polymères, F-75005

30 Paris, France.E-mail: laurent.bouteiller@upmc.fr

${ }^{b}$ CNRS, UMR 7610, Chimie des Polymères, F-75005 Paris, France

$\dagger$ Electronic Supplementary Information (ESI) available: Synthesis and additional SANS and FTIR data. See DOI: 10.1039/b000000x/

1 M. Mammen, E. E. Simanek and G. M. Whitesides, J. Am. Chem. Soc., 1996, 118, 12614.

2 A. P. Bisson, F. J. Carver, D. S. Eggleston, R. C. Haltiwanger, H. C. A., D. L. Livingstone, J. F. McCabe, C. Rotger and A. E. Rowan, J. Am. Chem. Soc., 2000, 122, 8856.

3 T. Mes, M. M. J. Smulders, A. R. A. Palmans and E. W. Meijer, Macromolecules, 2010, 43, 1981.

4 J. L. Cook, C. A. Hunter, C. M. R. Low, A. Perez-Velasco and J. G. Vinter, Angew. Chem. Int. Ed., 2007, 46, 3706.
5 T. Rehm and C. Schmuck, Chem. Commun., 2008, 801.

6 K. J. C. van Bommel, C. van der Pol, I. Muizebelt, A. Friggeri, A.

45 Heeres, A. Meetsma, B. L. Feringa and J. van Esch, Angew. Chem. Int. Ed., 2004, 43, 1663.

7 E. Obert, M. Bellot, L. Bouteiller, F. Andrioletti, C. LehenFerrenbach and F. Boué, J. Am. Chem. Soc., 2007, 129, 15601.

8 V. M. Rotello, E. A. Viani, G. Deslongchqmps, B. A. Murray and J. 50 Julius Rebek, J. Am. Chem. Soc., 1993, 115, 797.

9 J. H. K. K. Hirschberg, L. Brunsveld, A. Ramzi, J. A. J. M. Vekemans, R. P. Sijbesma and E. W. Meijer, Nature, 2000, 407, 167.

10 H. Fenniri, P. Mathivanan, K. L. Vidale, D. M. Sherman, K. Hallenga, K. V. Wood and J. G. Stowell, J. Am. Chem. Soc., 2001, 123, 3854

11 G. Borzsonyi, R. L. Beingessner, T. Yamazaki, J.-Y. Cho, A. J. Myles, M. Malac, R. Egerton, M. Kawasaki, K. Ishizuka, A. Kovalenko and H. Fenniri, J. Am. Chem. Soc., 2010, 132, 15136.

12 C. Schmuck and W. Wienand, J. Am. Chem. Soc., 2003, 125, 452

6013 T. H. Rehm and C. Schmuck, Chem. Soc. Rev., 2010, 39, 3597.

14 J. T. Davis and G. P. Spada, Chem. Soc. Rev., 2007, 36, 296.

15 G. V. Oshovsky, D. N. Reinhoudt and W. Verboom, Angew. Chem. Int. Ed., 2007, 46, 2366.

16 F. Huang, D. S. Nagvekar, X. Zhou and H. W. Gibson, Macromolecules, 2007, 40, 3561 .

17 H. Yamaguchi, D. S. Nagvekar and H. W. Gibson, Angew. Chem. Int. Ed., 1998, 37, 2361

18 S. V. Kolotuchin and S. C. Zimmerman, J. Am. Chem. Soc., 1998 , 120, 9092

7019 J. L. Atwood, L. J. Barbour and A. Jerga, Chem. Commun., 2001, 2376.

20 E. M. Todd and S. C. Zimmerman, Tetrahedron, 2008, 64, 8558.

21 R. Schmidt, M. Stolte, M. Grüne and F. Würthner, Macromolecules, 2011, 44, 3766.

7522 L. Bouteiller, Adv. Polym. Sci., 2007, 207, 79.

23 W. C. Yount, H. Juwarker and S. L. Craig, J. Am. Chem. Soc., 2003, $\mathbf{1 2 5}, 15302$.

24 Organogelators, which self-assemble into elongated (usually crystalline) fibrillar structures, are also used as additives for coatings,

80 but are usually not dynamic, i.e. not self-healing. For a review, see J. W. Steed, Chem. Commun., 2011, 47, 1379.

25 T. Shikata, T. Nishida, B. Isare, M. Linares, R. Lazzaroni and L. Bouteiller, J. Phys. Chem. B 2008, 112, 8459.

26 M. Bellot and L. Bouteiller, Langmuir 2008, 24, 14176.

8527 V. Simic, L. Bouteiller and M. Jalabert, J. Am. Chem. Soc. 2003, 125, 13148 .

28 B. Isare, M. Linares, R. Lazzaroni and L. Bouteiller, J. Phys. Chem. B 2009, 113, 3360.

29 A more polar oligoethylene glycol side chain was not considered 90 because it has been shown to form intramolecular hydrogen bonds in similar situations. See T. F. A. de Greef, M. M. L. Nieuwenhuizen, P. J. M. Stals, C. F. C. Fitie, A. R. A. Palmans, R. P. Sijbesma and E. W. Meijer, Chem. Commun., 2008, 4306.

30 F. Lortie, S. Boileau, L. Bouteiller, C. Chassenieux, B. Demé, G. 95 Ducouret, M. Jalabert, F. Lauprêtre and P. Terech, Langmuir 2002, 18, 7218 .

31 L. Bouteiller, O. Colombani, F. Lortie and P. Terech, J. Am. Chem. Soc. 2005, 127, 8893.

32 We assume a repeat distance of $4.6 \AA$, which is the distance between 100 hydrogen bonded urea groups in 1,3-dimethylurea crystals..$^{30,31}$

33 F. Lortie, S. Boileau and L. Bouteiller, Chem. Eur. J. 2003, 9, 3008.

34 M. Raynal and L. Bouteiller, Chem. Commun. 2011, 47, 8271.

35 A. Arnaud and L. Bouteiller, Langmuir 2004, 20, 6858. 